\title{
Determination of Natural Resistance Frequencies in Penicillium digitatum Using a New Air-Sampling Method and Characterization of Fludioxonil- and Pyrimethanil-Resistant Isolates
}

\author{
L. Kanetis, H. Förster, and J. E. Adaskaveg
}

First and third authors: Department of Plant Pathology and Microbiology, University of California, Riverside 92521; and second author: Department of Plant Pathology, University of California, Davis 95616.

Current address of first author: Department of Agricultural Sciences, Biotechnology and Food Science, Cyprus University of Technology, CY-3603 Lemesos, Cyprus.

Accepted for publication 12 April 2010.

\begin{abstract}
Kanetis, L., Förster, H., and Adaskaveg, J. E. 2010. Determination of natural resistance frequencies in Penicillium digitatum using a new airsampling method and characterization of fludioxonil- and pyrimethanilresistant isolates. Phytopathology 100:738-746.

Fungicide resistance was identified in natural populations of Penicillium digitatum, the causal agent of green mold of citrus, to two of three new postharvest fungicides before their commercial use. Using a new air-sampling method where large populations of the pathogen in citrus packinghouses were exposed to agar plates with a continuous, wide-range fungicide concentration gradient, isolates with reduced sensitivity to fludioxonil or pyrimethanil were obtained. Resistance frequencies to fludioxonil and pyrimethanil were calculated as $9.5 \times 10^{-7}$ to $1.5 \times 10^{-5}$ and $7.3 \times 10^{-6}$ to $6.2 \times 10^{-5}$, respectively. No isolates resistant to azoxystrobin were detected. Isolates with reduced sensitivity to fludioxonil or pyrimethanil were also obtained in laboratory selection studies, where high concentrations of conidial mixtures of isolates sensitive to the three fungicides were plated onto agar amended with each fungicide at $10 \mu \mathrm{g} / \mathrm{ml}$. Isolates obtained from fludioxonil selection plates in laboratory and packinghouse experiments were placed into two categories based on mycelial growth: moderately resistant isolates had $50 \%$ effective concentration $\left(\mathrm{EC}_{50}\right)$ values of 0.1 to $0.82 \mu \mathrm{g} / \mathrm{ml}$ and highly resistant isolates had $\mathrm{EC}_{50}$ values $>1.5 \mu \mathrm{g} / \mathrm{ml}$. Isolates resistant to

pyrimethanil all had $\mathrm{EC}_{50}$ values $>8 \mu \mathrm{g} / \mathrm{ml}$. Representative isolates of the two categories with reduced sensitivity to fludioxonil varied widely in their virulence and sporulation capacity as measured by the incidence of decay and degree of sporulation on inoculated fruit, respectively, whereas pyrimethanil-resistant isolates were mostly similar to the wild-type isolate. Fungicide sensitivity characteristics for isolates from fludioxonil and pyrimethanil selection plates remained stable after passages on nonamended agar, and disease could not be controlled after treatment with the respective fungicides. Types of fungicide resistance were visualized on thiabendazole- (TBZ) and imazalil-amended selection plates that were exposed in packinghouses where resistance to these fungicides was known to occur. The qualitative, single-site resistance to the benzimidazole TBZ was visualized by two distinct subpopulations in regard to fungicide sensitivity, whereas the quantitative, multi-site resistance to the demethylation inhibitor imazalil was apparent as a continuous density gradient of colonies along the fungicide concentration gradient. Types of resistance could not be assigned to fludioxonil or pyrimethanil because a limited number of resistant colonies was obtained on each plate. Thus, with this new method, we were able to estimate fungicide resistance frequencies as well as characterize and visualize types of resistance within populations of a fungal species. This information will be used to design resistance management strategies for previous and newly registered postharvest fungicides of citrus.
\end{abstract}

The development of fungicide resistance has greatly impacted the management of many pre- and postharvest fungal diseases. Among postharvest pathogens, species of Penicillium have a particularly high risk of becoming resistant to fungicides, mainly due to the pathogens' enormous asexual reproduction potential (16). Thus, a higher number of individuals less sensitive to a fungicide within these pathogen populations may occur than for many other fungi, and these individuals may be favored if the selection pressure continues. In postharvest management of citrus decays, this risk of fungicide resistance development in Penicillium populations is exacerbated by the year-round availability of susceptible host tissues because, in packinghouse operations, fruit are received, processed, and stored almost continuously. Furthermore, in California lemon (Citrus limon (L.) N. L. Burm.) production, fruit are often stored for extended times based on market needs and economic incentives. Decay commonly develops in storage and, during fruit processing before marketing, fungal

Corresponding author: J. E. Adaskaveg; E-mail address: jim.adaskaveg@ucr.edu

doi:10.1094/PHYTO-100-8-0738

(c) 2010 The American Phytopathological Society inoculum easily spreads in the packinghouse to healthy fruit and to fruit coming from the field if strict sanitation practices are not followed.

Thiabendazole (TBZ) and imazalil, two postharvest fungicides that have been used by the citrus industry for $>25$ years, have been the primary postharvest treatments for managing the major postharvest decays of citrus, green mold caused by Penicillium digitatum (Pers.) Sacc. and blue mold caused by $P$. italicum Wehmer. Resistance to these two fungicides is widespread in pathogen populations, and treatment efficacy of these originally highly effective compounds is often compromised $(5,10,17)$. Resistance to the benzimidazole TBZ is characterized as qualitative because a sudden shift from sensitivity to high-level resistance occurs due to mutation of a single or small number of major genes (16). Resistance to the demethylation inhibitor imazalil is characterized as quantitative or multi-step due to the mutation of several genes, each contributing to the development of fungicide insensitivity and leading to a gradual decrease in fungicide efficacy (16). Three new postharvest fungicides have been recently registered in the United States on citrus: the quinone outside inhibitor (QoI) azoxystrobin, the phenylpyrrole fludioxonil, and the anilinopyrimidine pyrimethanil (12). No resistance to these 
new fungicides in Penicillium spp. of citrus has been reported to date in packinghouses and the potential to develop resistance is not known.

To prevent or delay the development of resistance, treatment strategies that include sanitation, the use of fungicide mixtures, and optimal application methods have been developed for an integrated decay management system (14). In addition, routine monitoring for fungicide resistance is a common practice in many packinghouses, with the goal of detecting any shifts in fungicide sensitivity in the pathogen population at an early stage so that treatment strategies can be adjusted and the build-up of resistance may be avoided.

The standard monitoring method involves the exposure of agar plates amended with a discriminatory concentration of the fungicide of interest in the packinghouse (1). These plates are incubated and development of Penicillium spp. colonies is compared with nonamended plates that were exposed at the same time. This method has served the industry well in determining current resistance frequencies for imazalil and TBZ where resistance has been well characterized. For the newly registered fungicides, however, where baseline sensitivity ranges are known but resistance has not been described under field conditions, single discriminatory concentrations needed for effective monitoring programs have not been determined. This deficiency will render the use of the standard air-sampling technique problematic and, especially if quantitative resistance with a range of insensitivities is involved, an accurate assessment of fungicide sensitivity in a pathogen population will not be obtained. Furthermore, rare phenotypes are likely to remain undetected using this method because only a limited number of isolates is being evaluated.

Because the early detection of resistance is important for prolonging the effectiveness of the newly registered citrus postharvest fungicides (i.e., azoxystrobin, fludioxonil, and pyrimethanil) (22), one objective of our study was to develop a new airsampling technique for citrus packinghouses that does not require prior knowledge about potential degrees of resistance. Other objectives were to obtain an estimate of the natural resistance frequencies in populations of $P$. digitatum for these new fungicides as an indicator for the risk for resistance development under field conditions and to characterize resistant isolates that were recovered in these studies. Furthermore we used the new air-sampling method to visualize frequencies and degrees as well as types of resistance for imazalil and TBZ in air samplings of packinghouses where resistance in $P$. digitatum to these two fungicides was known to occur.

\section{MATERIALS AND METHODS}

Fungal isolates and fungicides. Isolates of $P$. digitatum were maintained as mycelial plugs in sterile water at $4{ }^{\circ} \mathrm{C}$ for up to 1 year. The single-spore isolate $\mathrm{Pd}$ that is sensitive to all fungicides included in the current study was used as a reference culture. Isolates used in the laboratory selection studies (see below) were part of baseline populations that were previously characterized for their fungicide sensitivity (13). Additional isolates were collected from decaying fruit in citrus packinghouses and were single spored before use. For conidial production, mycelial plugs were transferred to potato dextrose agar (PDA) (Difco Laboratories, Detroit, MI) and petri dishes were incubated for 5 to 10 days at $25^{\circ} \mathrm{C}$. Spore inoculum was prepared in $0.01 \%$ Tween 20 (Sigma-Aldrich, St. Louis, MO) and adjusted to $1 \times 10^{6}$ conidia/ml with sterile water. Single-spore colonies were produced from spore suspensions $(\approx 2,000$ conidia $/ \mathrm{ml})$ that were vortexed for $1 \mathrm{~min}$ to separate conidial chains before plating onto 10-cm PDA dishes using a spiral plater (Autoplate 4000; Spiral Biotech, Norwood, MA) set for the exponential application mode. Colonies developing in the most diluted area of the agar plate were transferred and were considered single-spore isolates.
Fungicides used were formulated products of azoxystrobin (Abound 2.08F; Syngenta Crop Protection, Greensboro, NC), fludioxonil (Scholar 50WP; Syngenta Crop Protection), imazalil (Freshgard 700; Janssen Pharmaceutica, Titusville, NJ), pyrimethanil (Penbotec 400SC; Janssen Pharmaceutica and Scala 600SC; Bayer CropScience, Kansas City, MO), and thiabendazole (TBZ; Mertect 340-F; Syngenta Crop Protection). Aqueous solutions of the fungicides were used in all assays. All fungicide concentrations were based on the active ingredient.

Estimation of resistance frequencies in populations of $\boldsymbol{P}$. digitatum for fludioxonil and pyrimethanil in laboratory selection studies. For selection of resistant isolates, conidial suspensions of mixtures of single-spore isolates of $P$. digitatum were plated onto petri dishes $(150 \mathrm{~mm}$ in diameter $)$ containing PDA amended with either fludioxonil or pyrimethanil at $10 \mu \mathrm{g} / \mathrm{ml}$. For fludioxonil, mixtures of 24 baseline isolates from a previous study (13) $\left(2.5 \times 10^{9}\right.$ conidia/ml $)$ or 42 newly obtained isolates from decayed lemon fruit in a packinghouse $\left(3 \times 10^{9}\right.$ conidia $\left./ \mathrm{ml}\right)$ were used. For pyrimethanil, mixtures of 24 baseline isolates or an additional 21 isolates from lemon fruit in a citrus packinghouse (both at $1 \times 10^{6}$ conidia/ml) were used. In addition to the baseline isolates, all newly obtained isolates were determined to be azoxystrobin-, fludioxonil-, and pyrimethanil-sensitive (described below). Each of these conidial suspensions contained an equal number of conidia from each mixture isolate. Suspensions were plated out with a spiral plater using the uniform mode of application, where $63.5 \mu \mathrm{l}$ of suspension is uniformly spread onto the agar surface. This resulted in a deposition of $1.6 \times 10^{8}$ or $1.9 \times$ $10^{8}$ conidia/plate for fludioxonil and $6.3 \times 10^{4}$ conidia/plate for pyrimethanil. For each spore suspension, 5 to 10 selection plates (replications) were used. After 3 days of incubation at $25^{\circ} \mathrm{C}$, the number of green sporulating colonies of $P$. digitatum was recorded for each plate. The resistance frequency (Rf) was calculated as the proportion of the number of these putative resistant colonies of the total number of conidia plated. A subset of 13 colonies for each fungicide was transferred to nonamended PDA plates using a sterile toothpick and single-spore isolates were obtained that were characterized for their sporulation capacity using a scale of 0 to 4 (where $0=$ no or negligible sporulation and $1=\leq 25,2=26$ to $50,3=51$ to 75 , and $4=\geq 76 \%$ of the colony surface with green sporulation) and evaluated in fungicide sensitivity and lemon fruit inoculation tests.

Estimation of resistance frequencies in populations of $P$. digitatum for fludioxonil, pyrimethanil, and azoxystrobin in air samplings of citrus packinghouses. Resistant isolates in citrus packinghouses were selected in samplings for airborne spores. These studies were conducted in three packinghouses in the late spring season when decay levels of stored fruit are usually the highest of the year. Fungicide-amended agar plates $(15 \mathrm{~cm}$ in diameter) that were used for sampling were prepared by spiral gradient dilution (SGD) 4 to $24 \mathrm{~h}$ before sampling using the exponential deposition mode of the spiral plater (6). For fludioxonil and pyrimethanil, PDA was used, whereas, for azoxystrobin, PDA was amended with salicylhydroxamic acid (SHAM; SigmaAldrich) at $100 \mu \mathrm{g} / \mathrm{ml}$ prepared in $50 \%$ ethanol and added to the cooled media. After spiral plating of the fungicides, these plates contained a continuous radial fungicide concentration gradient, with the highest concentration in the center of the plate and the lowest concentration at the edge of the plate. The $95 \%$ effective concentration $\left(\mathrm{EC}_{95}\right)$ sensitivity range for each fungicide as established for mycelial growth of baseline populations (i.e., $0.13 \mu \mathrm{g} / \mathrm{ml}$ for fludioxonil, $0.21 \mu \mathrm{g} / \mathrm{ml}$ for azoxystrobin, and $0.30 \mu \mathrm{g} / \mathrm{ml}$ for pyrimethanil) was located $\approx 1.5$ to $2.5 \mathrm{~cm}$ from the edge of the petri dish (13). The required stock solutions to obtain this were calculated using the SGE software (version 1.1; Spiral Biotech, Inc.) and were determined to be $500 \mu \mathrm{g} / \mathrm{ml}$ for fludioxonil and $1,000 \mu \mathrm{g} / \mathrm{ml}$ for azoxystrobin and pyrimethanil. These stock solutions resulted in radial concentration gradients of 0.026 to $4.0 \mu \mathrm{g} / \mathrm{ml}$ 
for fludioxonil, 0.037 to $7.7 \mu \mathrm{g} / \mathrm{ml}$ for azoxystrobin, and 0.063 to $7.8 \mu \mathrm{g} / \mathrm{ml}$ for pyrimethanil.

For air sampling, plates were exposed with their lids removed in areas of the packinghouse with a high spore load (i.e., areas where lemon fruit are taken out of storage to be processed for shipping) or in storage rooms. Exposure times were 0.5 to $5 \mathrm{~min}$, depending on the amount of Penicillium decay observed on the fruit. To minimize the amount of contamination with Rhizopus and Mucor spp., plates were placed at least $1 \mathrm{~m}$ above the floor level. For each fungicide, five selection plates were used in each of four sampling studies (two samplings in each of two packinghouses conducted on different dates). Plates were taken back to the laboratory and incubated as described for the laboratory selection studies. Similarly, the number of colonies growing at fungicide concentrations $>\mathrm{EC}_{95}$ were enumerated and a subsample of colonies ( 5 to 20 sporulating colonies for each experiment, resulting in a total of 40 colonies) was cultured, single spored, and further characterized similar to isolates derived from the laboratory selection studies.

To estimate the average number of spores deposited onto the plates at each sampling, $15-\mathrm{cm}$ petri dishes containing $50 \mathrm{ml}$ of $0.01 \%$ (vol/vol) Tween 20 were exposed simultaneously with the fungicide selection plates. Conidial counts were obtained using a hemacytometer and the average total number of conidia in the $50 \mathrm{ml}$ of solution was calculated from three replicated plates and used for calculating $\mathrm{Rf}$ values as described above for the laboratory selection studies.

Determination of in vitro fungicide sensitivities of putative resistant isolates of $\boldsymbol{P}$. digitatum. The $50 \%$ effective concentration $\left(\mathrm{EC}_{50}\right)$ values for inhibition of mycelial growth were determined using the SGD method as described previously $(6,13)$. Stock concentrations plated onto PDA plates for azoxystrobin (PDA-SHAM was used for this fungicide), fludioxonil, imazalil, pyrimethanil, and TBZ were 100, 50 and 200, 30 and 200, 100 and 1,000 , and 200 and $1,000 \mu \mathrm{g} / \mathrm{ml}$, respectively. After 3 to $4 \mathrm{~h}$ of incubation to allow a continuous fungicide gradient to form, $10-\mu l$ droplets of conidial suspensions $\left(1 \times 10^{6}\right.$ conidia $\left./ \mathrm{ml}\right)$ of $P$. digitatum were streaked out radially across the gradient. After 3 days of incubation at $25^{\circ} \mathrm{C}$, the radial distance where mycelial growth was inhibited by $50 \%$ compared with the control was entered into the SGE software and translated into a local fungicide concentration (6). Isolates were rated for their sensitivity to each fungicide in comparison with baseline sensitivity values (13) and were categorized as sensitive ( $\mathrm{S}$; $\mathrm{EC}_{50}$ value within baseline), sensitive but outside baseline $\left(\mathrm{S}-\mathrm{OBL} ; \mathrm{EC}_{50}\right.$ value $<10$ times above baseline), or resistant $\left(\mathrm{R} ; \mathrm{EC}_{50}\right.$ value at least 10 times the baseline value). For fludioxonil, resistant isolates were differentiated as moderately resistant (MR; $\mathrm{EC}_{50}$ value of 0.1 to $0.82 \mu \mathrm{g} / \mathrm{ml}$ ) or highly resistant (HR; $\mathrm{EC}_{50}$ value $>1.5 \mu \mathrm{g} / \mathrm{ml}$ ).

Evaluation of pathogenicity, virulence, sporulation capacity, and response of resistant isolates to fungicide treatments in lemon fruit inoculation studies. Lemon fruit cv. Eureka grown using commercial practices and without the use of any preharvest fungicide treatments were hand washed in water with a dishwashing detergent, surface disinfested by dipping into sodium hypochlorite $(100 \mu \mathrm{g} / \mathrm{ml})$, rinsed with tap water, and placed into plastic fruit trays in cardboard fruit boxes. For evaluation of pathogenicity (ability to cause disease), virulence (incidence of decay), sporulation capacity (amount of asexual reproduction), and response to fungicide treatments, fruit were wounded using a 1-by-2-mm nail-like, stainless-steel probe without injuring the juice sacks below the albedo and then inoculated with $20-\mu$ l drops of inoculum $\left(1 \times 10^{6}\right.$ conidia $\left./ \mathrm{ml}\right)$ of $P$. digitatum. For evaluation of the sporulation capacity on decaying fruit, lemon fruit were inoculated at the center of the fruit using a syringe. Representative isolates from packinghouse selections less sensitive to fludioxonil (12MR, 13HR, FL7, and FL12) or pyrimethanil (1, $10 \mathrm{a}, 5 \mathrm{AP}$, and $\mathrm{BF}$ ) were compared with the sensitive isolate $\mathrm{Pd}$.
Fruit boxes were covered with plastic bags and incubated at $20^{\circ} \mathrm{C}$ and $>90 \%$ relative humidity for 14 to $16 \mathrm{~h}$. For treatment, fruit were sprayed with aqueous solutions of azoxystrobin, fludioxonil, imazalil, pyrimethanil, or TBZ, (all at $1,000 \mu \mathrm{g} / \mathrm{ml}$ ) on the inoculated side using a hand-operated atomizer (Model 15-RD; DeVilbiss Health Care, Somerset, PA). Fruit for sporulation evaluation were only treated with fludioxonil or pyrimethanil. Fruit of the control treatment were sprayed with water. Fruit boxes covered with plastic bags were incubated for 6 to 7 days at $20^{\circ} \mathrm{C}$ and $>90 \%$ relative humidity. Fruit were then inspected carefully for green mold development that was either easily visible as mycelium- or conidia-covered decay or was present as soft, often watery lesions around the inoculation site. Virulence was determined based on the disease incidence that was calculated using the number of decayed fruit divided by the total number of fruit inoculated. Sporulation capacity was determined based on fungal sporulation on the fungicidetreated side of the fruit and was rated using a scale of 0 to 4 , where $0=$ no or negligible sporulation and $1=\leq 25,2=26$ to 50 , $3=51$ to 75 , and $4=\geq 76 \%$ of the fruit surface with green sporulation. There were three to four replications of 10 to 15 fruit for each treatment and experiments were performed two or three times.

Visualization of qualitative and quantitative types of fungicide resistance on fungicide selection plates after air sampling of $\boldsymbol{P}$. digitatum populations in citrus packinghouses. SGD selection plates were prepared as described above using a spiral plater but plates were amended with imazalil or TBZ. Stock concentrations applied were $200 \mu \mathrm{g} / \mathrm{ml}$ for imazalil and $600 \mu \mathrm{g} / \mathrm{ml}$ for TBZ. This again localized the $95 \%$ inhibitory concentrations of the two fungicides (i.e., 0.047 and $0.29 \mu \mathrm{g} / \mathrm{ml}$ for imazalil and TBZ, respectively) within 10 to $15 \mathrm{~mm}$ of the outer periphery of the agar plates. Three replicate plates in each of two experiments were exposed to airborne populations of $P$. digitatum as described above in a citrus packinghouse where resistance was known to occur. After incubation, fungal growth on the plates was characterized based on the distribution and density of colonies. Cultures were established from colonies derived within the inner zone, where fungicide concentrations are greater than the $\mathrm{EC}_{95}$ values (i.e., 20 to $49 \mathrm{~mm}$ from the center of the plate) and the outer zone, where fungicide concentrations are lower than the $\mathrm{EC}_{95}$ values (i.e., 15 to $25 \mathrm{~mm}$ from the periphery) of the plate and, in total, 9 to 21 colonies from each zone were evaluated for their fungicide sensitivity. Stock concentrations applied to SGD plates for colonies from imazalil selection plates were imazalil at 30 and $200 \mu \mathrm{g} / \mathrm{ml}$ and concentrations for colonies from TBZ selection plates were TBZ at 200 and $1,000 \mu \mathrm{g} / \mathrm{ml}$.

Statistical analysis of data. Data for decay incidence were arcsine transformed. Bartlett's test for homogeneity of variances was performed for repeated experiments. Data sets with homogeneous variances $(P<0.05)$ were combined and then analyzed using a one- or two-way arrangement of data depending on the experiment. For error control, all treatments were in a randomized complete-block design. Values were analyzed using general linear model or analysis of variance and least significant difference (LSD) mean separation procedures of SAS (version 9.1; SAS Institute, Cary, NC).

\section{RESULTS}

Estimation of resistance frequencies in populations of $\boldsymbol{P}$. digitatum for fludioxonil and pyrimethanil in laboratory selection studies. In each of the two experiments conducted, sporulating colonies of $P$. digitatum developed on selection plates amended with fludioxonil or pyrimethanil at $10 \mu \mathrm{g} / \mathrm{ml}$. For these putative resistant isolates, $\mathrm{Rf}$ values were calculated based on the total number of conidia applied to a single plate. For fludioxonil, similar $(P=0.069)$ average $\mathrm{Rf}$ values were obtained for the two 
experiments that ranged from $9.7 \times 10^{-8}$ to $1.3 \times 10^{-7}$ (Table 1 ). For pyrimethanil, values from different experiments were significantly $(P=0.017)$ different and ranged from $6.9 \times 10^{-5}$ to $1.1 \times$ $10^{-4}$.

When colonies were transferred onto nonamended agar media, cultural morphology, including the amount of sporulation of colonies obtained from pyrimethanil-amended plates, was similar to the wild-type isolate Pd (rating of 4 for each). Colonies originating from the fludioxonil selection plates, however, showed reduced sporulation (rating of 2.5) compared with isolate $\mathrm{Pd}$ (rating of 4).

Estimation of resistance frequencies in populations of $P$. digitatum for fludioxonil, pyrimethanil, and azoxystrobin in air samplings of citrus packinghouses. Representative airsampling plates for fludioxonil, pyrimethanil, and azoxystrobin after 3 days of incubation are shown in Figure 1A, B, and C, respectively. For fludioxonil and pyrimethanil, a high density of $P$. digitatum colonies was found as a concentric ring in the outer periphery of the plate where local fungicide concentrations were less than the $\mathrm{EC}_{95}$ values. After 5 days of incubation, most of these colonies were sporulating with the typical green color of $P$. digitatum. A low number of colonies (generally $<20$ ) was present in the higher fungicide concentration range toward the center of the plate. Most of these colonies remained $<1 \mathrm{~mm}$ in diameter and never produced spores but a few started expanding and sporulating. These latter colonies were considered putative resistant isolates and were cultured on PDA not amended with fungicides, single spored, and characterized in subsequent studies. Based on the number of putative resistant colonies and the total number of spores deposited on each plate that was derived from spore counts in dishes with an aqueous Tween 20 solution (estimated between $1.0 \times 10^{5}$ and $4.1 \times 10^{6}$ conidia/plate), $\mathrm{Rf}$ values were calculated. For fludioxonil, no significant $(P=0.267)$ difference among average $\mathrm{Rf}$ values for the four air samplings was found although values ranged from $9.5 \times 10^{-7}$ to $1.5 \times 10^{-6}$ (Table 1 ). For pyrimethanil, three of the samplings resulted in similar $\mathrm{Rf}$ values $\left(7.3 \times 10^{-6}\right.$ to $\left.4.7 \times 10^{-6}\right)$, whereas a forth one had a significantly $(P<0.0001)$ higher frequency of $6.2 \times 10^{-5}$ (Table 1$)$.

TABLE 1. Estimates of resistance frequencies for fludioxonil and pyrimethanil in populations of Penicillium digitatum based on laboratory studies or packinghouse air samplings

\begin{tabular}{ll}
\hline Fungicide, population $^{\mathrm{y}}$ & Resistance frequency $^{\mathrm{z}}$ \\
\hline Fludioxonil & \\
Lab-1 & $1.3 \times 10^{-7} \mathrm{a}$ \\
Lab-2 & $9.7 \times 10^{-8} \mathrm{a}$ \\
Air-sampling 1 & $7.4 \times 10^{-7} \mathrm{a}$ \\
Air-sampling 2 & $3.9 \times 10^{-7} \mathrm{a}$ \\
Air-sampling 3 & $9.5 \times 10^{-7} \mathrm{a}$ \\
Air-sampling 4 & $1.5 \times 10^{-6} \mathrm{a}$ \\
Pyrimethanil & \\
Lab-1 & $1.1 \times 10^{-4} \mathrm{a}$ \\
Lab-2 & $6.9 \times 10^{-5} \mathrm{~b}$ \\
Air-sampling 1 & $7.3 \times 10^{-6} \mathrm{a}$ \\
Air-sampling 2 & $5.6 \times 10^{-6} \mathrm{a}$ \\
Air-sampling 3 & $6.2 \times 10^{-5} \mathrm{~b}$ \\
Air-sampling 4 & $4.7 \times 10^{-6} \mathrm{a}$ \\
\hline
\end{tabular}

y In laboratory studies, conidial mixtures of 24 (experiment Lab-1) or 42 (experiment Lab-2) isolates (1.5 to $1.9 \times 10^{8}$ conidia/selection plate) for fludioxonil and 24 (experiment Lab-1) and 21 (experiment Lab-2) isolates $\left(6.3 \times 10^{4}\right.$ conidia/plate $)$ for pyrimethanil were plated onto fungicideamended media. In packinghouse studies, $5.3 \times 10^{5}$ to $4.1 \times 10^{6}$ conidia/ plate were air sampled for fludioxonil and $1.0 \times 10^{5}$ to $1.6 \times 10^{6}$ conidia/ plate were air sampled for pyrimethanil in four experiments.

z Resistance frequency (Rf) is the proportion of resistant isolates found per total number of conidia sampled. Each population (laboratory or packinghouse air sampling) was statistically analyzed separately. Rf values within each population followed by the same letter are not significantly different $(P>0.05)$ based on an analysis of variance and least significant difference mean separation procedures.
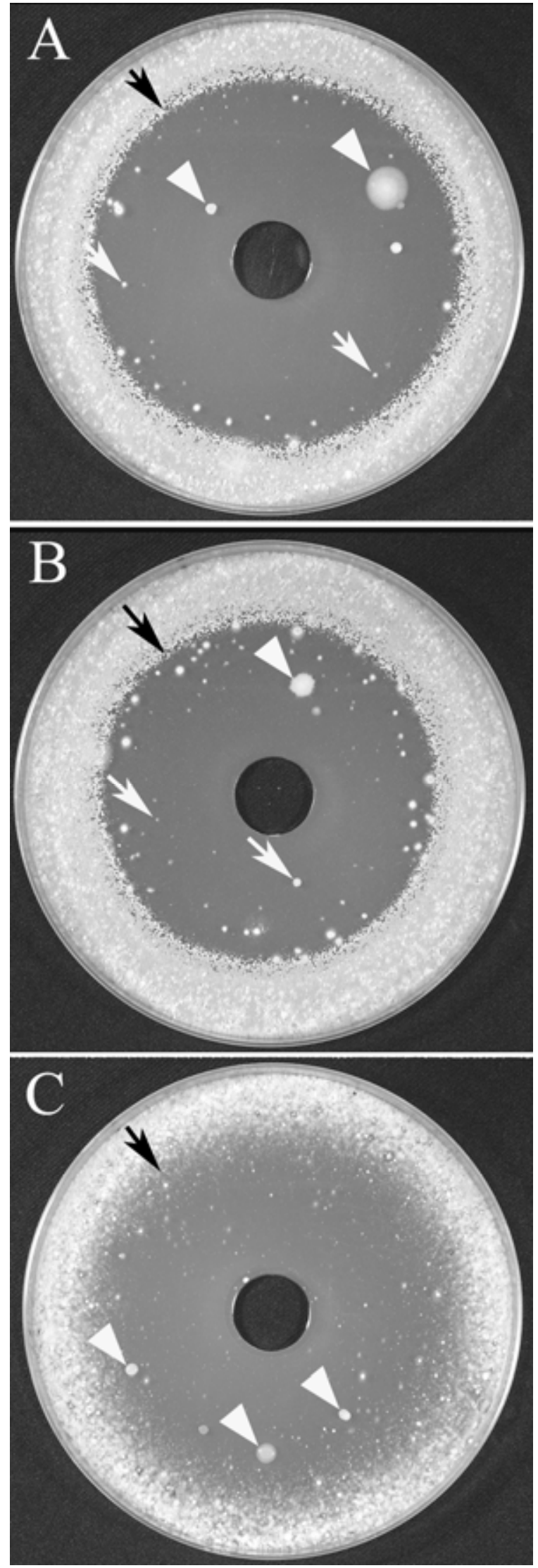

Fig. 1. Air-sampling spiral gradient dilution plates amended with A, fludioxonil; B, pyrimethanil; or $\mathbf{C}$, azoxystrobin. Black arrows indicate the location of the $95 \%$ effective concentration of each fungicide. White arrows indicate some of the putative resistant isolates of Penicillium digitatum. Arrowheads indicate some of the contaminating fungal or bacterial colonies that develop during air-sampling of commercial packinghouses. 
Selection plates amended with azoxystrobin also showed a high colony density in a concentric outer ring defined by fungicide concentrations of $\leq \mathrm{EC}_{95}$ (Fig. 1C). Colonies in this area enlarged and sporulated after 5 days of incubation. A density gradient of smaller nonsporulating colonies developed in areas of the selection plates with higher concentrations of azoxystrobin, with fewer colonies present at increasing concentrations. When these colonies were transferred to nonamended PDA, they slowly enlarged but then stopped growing and never produced conidia. These colonies were not further characterized.

The vast majority of fungi developing on the selection plates was identified as $P$. digitatum. In most samplings, colonies of $P$. italicum as well as Alternaria, Cladosporium, and Geotrichum spp. developed but did not interfere with our selection studies. Contamination with Rhizopus and Mucor spp. was minimized by placing selection plates at least $1 \mathrm{~m}$ above the ground level.

Fungicide sensitivities of putative resistant isolates of $\boldsymbol{P}$. digitatum. Putative fludioxonil- or pyrimethanil-resistant isolates were evaluated for their sensitivities to azoxystrobin, fludioxonil, pyrimethanil, imazalil, and TBZ. Results for representative isolates are shown in Table 2. All isolates evaluated were found to be sensitive to azoxystrobin, although $\mathrm{EC}_{50}$ values of some isolates were above the previously established baseline range (i.e., 0.007 to $0.028 \mu \mathrm{g} / \mathrm{ml})(13)$.

Isolates obtained from fludioxonil selection plates in laboratory and packinghouse experiments were designated as moderately or highly resistant (Table 2). $\mathrm{EC}_{50}$ values of moderately resistant isolates from the laboratory selections were all close to $1 \mu \mathrm{g} / \mathrm{ml}$, whereas those of packinghouse selections were 0.1 to $1 \mu \mathrm{g} / \mathrm{ml}$. All isolates from the fludioxonil selection plates were categorized as sensitive to pyrimethanil although one isolate had an $\mathrm{EC}_{50}$ value of $0.909 \mu \mathrm{g} / \mathrm{ml}$ and, thus, was above the baseline range of 0.208 to $0.413 \mu \mathrm{g} / \mathrm{ml}$. Isolates obtained in laboratory selections were sensitive to TBZ, whereas some isolates were resistant to imazalil. All isolates from the packinghouse selections were resistant to the latter two fungicides.

Isolates obtained from pyrimethanil selection plates in laboratory and packinghouse experiments were all resistant to pyrimethanil, with $\mathrm{EC}_{50}$ values $>8 \mu \mathrm{g} / \mathrm{ml}$, the highest concentration evaluated for pyrimethanil in the sensitivity studies. Highly resistant isolates had $\mathrm{EC}_{50}$ values $>1.58 \mu \mathrm{g} / \mathrm{ml}$. All isolates were sensitive to fludioxonil. Of the three isolates from laboratory studies that were evaluated for their imazalil and TBZ sensitivity, two were sensitive and one was resistant to both fungicides. All isolates from the packinghouse selections were resistant to imazalil and TBZ.

Fungicide sensitivities for fludioxonil and pyrimethanil of representative isolates were re-evaluated over the course of the studies. Resistance was found to remain stable using the same spiral gradient plate procedures and fruit inoculation assays (described below) after five to seven transfers on nonamended media and after storage at $4^{\circ} \mathrm{C}$ for 1 year (the longest storage time evaluated). These results are not presented.

Pathogenicity, virulence, sporulation capacity, and response of resistant isolates to fungicide treatments in lemon fruit inoculation studies. Pathogenicity was evaluated as the ability of isolates to cause decay of lemon fruit. All pyrimethanil- and fludioxonil-resistant isolates collected from selection plates were pathogenic. Fludioxonil-resistant isolates were either similarly (isolate 13HR) or significantly less (isolates FL7HR, FL12HR, and $12 \mathrm{MR}$ ) virulent than the wild-type isolate $\mathrm{Pd}$ (Table 3, data for "untreated"). Isolate $12 \mathrm{MR}$ caused green mold decay on $65 \%$ of the fruit but only $23.3 \%$ of the fruit developed decay after inoculation with isolates FL7HR or FL12HR compared with $100 \%$ for isolate $\mathrm{Pd}$. Three of the pyrimethanil-resistant isolates

TABLE 3. Efficacy of postharvest treatments against green mold decay of lemon fruit caused by isolates of Penicillium digitatum exhibiting different levels of sensitivity to fludioxonil

\begin{tabular}{|c|c|c|c|c|c|}
\hline \multirow[b]{3}{*}{ Treatment ${ }^{\mathrm{y}}$} & \multicolumn{5}{|c|}{ Incidence $(\%)^{\mathrm{Z}}$} \\
\hline & \multirow{2}{*}{$\frac{\text { Wild type }}{\mathrm{Pd}}$} & \multicolumn{4}{|c|}{ Resistant isolates } \\
\hline & & FL7HR & FL12HR & $12 \mathrm{MR}$ & $13 \mathrm{HR}$ \\
\hline Untreated & $100.0 \mathrm{~A} \mathrm{a}$ & $23.3 \mathrm{C} \mathrm{b}$ & $23.3 \mathrm{C} \mathrm{b}$ & $65.0 \mathrm{~B} \mathrm{a}$ & $90.0 \mathrm{~A} \mathrm{a}$ \\
\hline Azoxystrobin & $20.0 \mathrm{~A} \mathrm{~b}$ & $3.3 \mathrm{~B} \mathrm{c}$ & $0.0 \mathrm{~B} \mathrm{c}$ & $6.7 \mathrm{~B} \mathrm{bc}$ & $6.7 \mathrm{~B} \mathrm{c}$ \\
\hline Fludioxonil & $14.2 \mathrm{C} \mathrm{b}$ & $41.7 \mathrm{~B} \mathrm{a}$ & $33.3 \mathrm{~B} \mathrm{a}$ & $20.0 \mathrm{C} \mathrm{b}$ & $68.3 \mathrm{~A} \mathrm{~b}$ \\
\hline Imazalil & $0.0 \mathrm{~B} \mathrm{c}$ & $0.0 \mathrm{~B} \mathrm{~d}$ & $0.0 \mathrm{~B} \mathrm{c}$ & $8.3 \mathrm{~A} \mathrm{bc}$ & $3.3 \mathrm{AB} \mathrm{c}$ \\
\hline Pyrimethanil & $0.0 \mathrm{~A} \mathrm{c}$ & $0.0 \mathrm{~A} \mathrm{~d}$ & $0.0 \mathrm{~A} \mathrm{c}$ & $0.0 \mathrm{~A} \mathrm{c}$ & $0.0 \mathrm{~A} \mathrm{c}$ \\
\hline Thiabendazole & $0.0 \mathrm{C} \mathrm{c}$ & $0.0 \mathrm{C} \mathrm{d}$ & $5.0 \mathrm{C} \mathrm{c}$ & $16.7 \mathrm{~B} \mathrm{~b}$ & $70.0 \mathrm{~A} \mathrm{~b}$ \\
\hline
\end{tabular}

y All fungicides were applied as aqueous solutions at a concentration of $1,000 \mu \mathrm{g} / \mathrm{ml}$ using an air-nozzle sprayer $12 \mathrm{~h}$ after inoculation.

${ }^{\mathrm{z}}$ Decay incidence is the percentage of inoculated fruit with decay. Incidence values followed by the same letter within a row (capitalized letters) or column (small letters) are not significantly different $(P>0.05)$ following an analysis of variance and least significant difference mean separation procedures. Fludioxonil-resistant isolates were selected either in laboratory assays (FL7HR and FL12HR) or in air samplings in citrus packinghouses (12MR and 13HR) (see text for details). Isolate $\mathrm{Pd}$ is sensitive to all currently registered and new fungicides.

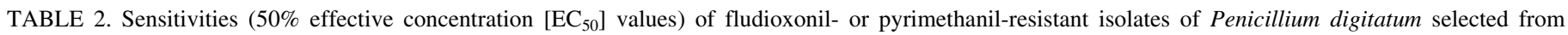
laboratory or packinghouse populations against citrus postharvest fungicides ${ }^{\mathrm{w}}$

\begin{tabular}{|c|c|c|c|c|c|c|c|c|c|c|c|}
\hline \multirow[b]{2}{*}{ Fungicide, loc. ${ }^{\mathrm{x}}$} & \multirow[b]{2}{*}{ Isolate } & \multicolumn{2}{|c|}{ Azoxystrobin ${ }^{y}$} & \multicolumn{2}{|c|}{ Fludioxonily } & \multicolumn{2}{|c|}{ Pyrimethanil ${ }^{\mathrm{y}}$} & \multicolumn{2}{|c|}{ Imazalil $^{\mathrm{z}}$} & \multicolumn{2}{|c|}{$\mathrm{TBZ}^{\mathrm{z}}$} \\
\hline & & $\mathrm{EC}_{50}(\mu \mathrm{g} / \mathrm{ml})$ & Sensitivity & $\mathrm{EC}_{50}(\mu \mathrm{g} / \mathrm{ml})$ & Sensitivity & $\mathrm{EC}_{50}(\mu \mathrm{g} / \mathrm{ml})$ & Sensitivity & $\mathrm{EC}_{50}(\mu \mathrm{g} / \mathrm{ml})$ & Sensitivity & $\mathrm{EC}_{50}(\mu \mathrm{g} / \mathrm{ml})$ & Sensitivity \\
\hline \multicolumn{12}{|l|}{ Fludioxonil } \\
\hline \multirow[t]{3}{*}{ Laboratory } & FL2MR & 0.028 & $\mathrm{~S}$ & 0.817 & MR & 0.289 & $S$ & 0.105 & S & 0.046 & $\mathrm{~S}$ \\
\hline & FL7HR & 0.038 & S-OBL & $\geq 1.58$ & HR & 0.310 & S & 0.022 & $\mathrm{~S}$ & 0.055 & $\mathrm{~S}$ \\
\hline & FL12HR & 0.027 & S & $\geq 1.58$ & HR & 0.190 & S & $\geq 0.24$ & $\mathrm{R}$ & 0.810 & $\mathrm{~S}$ \\
\hline \multirow[t]{4}{*}{ Packinghouse } & $7 \mathrm{MR}$ & 0.064 & S-OBL & 0.124 & MR & 0.162 & S & $\geq 0.24$ & $\mathrm{R}$ & $\geq 1.57$ & $\mathrm{R}$ \\
\hline & $12 \mathrm{MR}$ & 0.014 & $\mathrm{~S}$ & 0.191 & MR & 0.109 & $\mathrm{~S}$ & $\geq 0.24$ & $\mathrm{R}$ & $\geq 1.57$ & $\mathrm{R}$ \\
\hline & $13 \mathrm{HR}$ & 0.055 & S-OBL & $\geq 1.58$ & HR & 0.919 & S-OBL & $\geq 0.24$ & $\mathrm{R}$ & $\geq 1.57$ & $\mathrm{R}$ \\
\hline & $15 \mathrm{HR}$ & 0.077 & S-OBL & $\geq 1.58$ & HR & 0.160 & $\mathrm{~S}$ & $\geq 0.24$ & $\mathrm{R}$ & $\geq 1.57$ & $\mathrm{R}$ \\
\hline \multicolumn{12}{|l|}{ Pyrimethanil } \\
\hline \multirow[t]{3}{*}{ Laboratory } & $10 \mathrm{a}$ & 0.020 & $S$ & 0.009 & $\mathrm{~S}$ & $\geq 8$ & $\mathrm{R}$ & 0.020 & $\mathrm{~S}$ & 0.066 & $\mathrm{~S}$ \\
\hline & $10 \mathrm{~b}$ & 0.015 & $S$ & 0.009 & $\mathrm{~S}$ & $\geq 8$ & $\mathrm{R}$ & 0.020 & $\mathrm{~S}$ & 0.060 & $\mathrm{~S}$ \\
\hline & $5 \mathrm{AP}$ & 0.022 & $\mathrm{~S}$ & 0.023 & S & $\geq 8$ & $\mathrm{R}$ & $\geq 0.24$ & $\mathrm{R}$ & $\geq 1.57$ & $\mathrm{R}$ \\
\hline \multirow[t]{3}{*}{ Packinghouse } & $1 \mathrm{AP}$ & 0.078 & S-OBL & 0.026 & $\mathrm{~S}$ & $\geq 8$ & $\mathrm{R}$ & $\geq 0.24$ & $\mathrm{R}$ & $\geq 1.57$ & $\mathrm{R}$ \\
\hline & 9AP & 0.061 & S-OBL & 0.022 & $\mathrm{~S}$ & $\geq 8$ & $\mathrm{R}$ & $\geq 0.24$ & $\mathrm{R}$ & $\geq 1.57$ & $\mathrm{R}$ \\
\hline & $\mathrm{BF}$ & 0.029 & $\mathrm{~S}$ & 0.026 & $\mathrm{~S}$ & $\geq 8$ & $\mathrm{R}$ & $\geq 0.24$ & $\mathrm{R}$ & $\geq 1.57$ & $\mathrm{R}$ \\
\hline
\end{tabular}

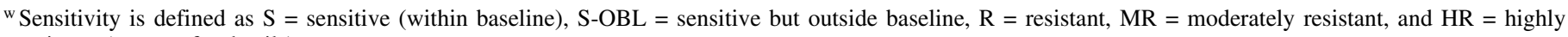
resistant (see text for details).

${ }^{x}$ Fungicide and location.

y Baseline sensitivity ranges for azoxystrobin, fludioxonil, and pyrimethanil are 0.007 to $0.028,0.009$ to 0.072 , and 0.208 to $0.413 \mu \mathrm{g} / \mathrm{ml}$, respectively (13).

${ }^{\mathrm{z}}$ Discriminatory concentrations used to characterize an isolate as resistant to imazalil or thiabendazole (TBZ) were $0.15 \mathrm{or} 1 \mu \mathrm{g} / \mathrm{ml}$, respectively. 
showed virulence similar to the wild-type isolate Pd whereas one isolate (i.e., 10a) was slightly but significantly less virulent, causing $79.1 \%$ of the fruit to decay compared with $94.3 \%$ of the wild-type isolate (Table 4, data for "untreated").

Inoculated fruit were treated with each of the fungicides and their efficacy in reducing decay caused by the wild-type and resistant isolates was evaluated. The effect of the applied fungicides on disease incidence was highly significant $(P<0.0001)$ and there was a highly significant $(P<0.0001)$ interaction between isolates and treatments. Thus, data are presented separately for each treatment and isolate in Tables 3 and 4.

Green mold development on fruit inoculated with the fungicide-sensitive wild-type isolate $\mathrm{Pd}$ was significantly reduced by treatments with all five fungicides at a concentration of $1,000 \mu \mathrm{g} / \mathrm{ml}$. Decay incidences were 0 to $20 \%$ compared with the untreated control, where 94.8 to $100 \%$ of the fruit developed green mold (Tables 3 and 4). After inoculation with either one of four fludioxonil-resistant isolates and treatment with fludioxonil, 20.0 to $68.3 \%$ of the fruit developed decay. The lowest incidence was observed for the intermediately resistant isolate 12MR (Table 3 ). Interestingly, incidence of decay caused by the two laboratoryselected highly resistant isolates FL7HR and FL12HR was significantly increased after treatment with fludioxonil compared with the untreated control for each isolate. Decay caused by fludioxonil-resistant isolates, however, was effectively controlled by treatments with azoxystrobin or pyrimethanil, resulting in a decay incidence of 0 to $6.6 \%$. Although one of the laboratoryselected isolates (FL12HR) and the two packinghouse-selected isolates were characterized as resistant to imazalil (Table 2), this fungicide reduced decay levels to $\leq 8.3 \%$. TBZ treatments prevented decay development after inoculation with the TBZ-sensitive isolate FL7HR whereas, for the three TBZ-resistant isolates, decay incidence was reduced by 22.2 to $78.5 \%$ compared with the untreated control for each isolate.

In contrast to fruit inoculated with the sensitive wild-type isolate $\mathrm{Pd}$, treatments with pyrimethanil were not very effective in reducing green mold when inoculated with any of the four pyrimethanil-resistant isolates evaluated (Table 4). For isolate BF, decay incidence was reduced to $72 \%$ compared with the control with $100 \%$. For isolate $10 \mathrm{a}$, all fruit developed green mold after pyrimethanil treatment. Treatments with azoxystrobin or fludioxonil were effective for all isolates of $P$. digitatum evaluated but there was a significant difference in efficacy, although in vitro sensitivities to these fungicides were very similar among isolates (Table 2). Treatments with imazalil reduced decay to $\leq 15.0 \%$ for

TABLE 4. Efficacy of postharvest treatments against green mold decay of lemon fruit caused by isolates of Penicillium digitatum resistant to pyrimethanil

\begin{tabular}{|c|c|c|c|c|c|}
\hline \multirow[b]{3}{*}{ Treatment ${ }^{\mathrm{y}}$} & \multicolumn{5}{|c|}{ Incidence $(\%)^{\mathrm{z}}$} \\
\hline & \multirow{2}{*}{$\frac{\text { Wild type }}{\mathrm{Pd}}$} & \multicolumn{4}{|c|}{ Resistant isolates } \\
\hline & & $5 \mathrm{AP}$ & $10 \mathrm{a}$ & $1 \mathrm{AP}$ & $\mathrm{BF}$ \\
\hline Untreated & $94.3 \mathrm{~A} \mathrm{a}$ & $95.8 \mathrm{~A} \mathrm{a}$ & $79.2 \mathrm{~B} \mathrm{a}$ & $100.0 \mathrm{~A} \mathrm{a}$ & $100.0 \mathrm{~A} \mathrm{a}$ \\
\hline Azoxystrobin & $3.8 \mathrm{BC} \mathrm{b}$ & $1.3 \mathrm{C} \mathrm{d}$ & $1.3 \mathrm{C} \mathrm{b}$ & $10.0 \mathrm{~B} \mathrm{e}$ & $23.2 \mathrm{~A} \mathrm{c}$ \\
\hline Fludioxonil & $5.0 \mathrm{BC} \mathrm{b}$ & $12.5 \mathrm{~B} \mathrm{c}$ & $2.5 \mathrm{C} \mathrm{b}$ & $23.3 \mathrm{~A} \mathrm{~d}$ & $11.6 \mathrm{~B} \mathrm{c}$ \\
\hline Imazalil & $0.0 \mathrm{C} \mathrm{c}$ & $7.5 \mathrm{~B} \mathrm{~cd}$ & $2.5 \mathrm{BC} \mathrm{b}$ & $8.3 \mathrm{~B} \mathrm{e}$ & $15.0 \mathrm{Ac}$ \\
\hline Pyrimethanil & $0.0 \mathrm{D} \mathrm{c}$ & $86.3 \mathrm{~B} \mathrm{~b}$ & $100.0 \mathrm{~A} \mathrm{a}$ & $80.0 \mathrm{BC} \mathrm{c}$ & $75.0 \mathrm{Cb}$ \\
\hline Thiabendazole & $0.0 \mathrm{D} \mathrm{c}$ & $100.0 \mathrm{~A} \mathrm{a}$ & $0.0 \mathrm{D} \mathrm{b}$ & $88.3 \mathrm{C} \mathrm{b}$ & $95.0 \mathrm{~B} \mathrm{a}$ \\
\hline
\end{tabular}

${ }^{y}$ All fungicides were applied as aqueous solutions at a concentration of $1,000 \mu \mathrm{g} / \mathrm{ml}$ using an air-nozzle sprayer $12 \mathrm{~h}$ after inoculation.

${ }^{z}$ Decay incidence is the percentage of inoculated fruit with decay. Incidence values followed by the same letter within a row (capitalized letters) or column (small letters) are not significantly different $(P>0.05)$ following an analysis of variance and least significant difference mean separation procedures. Pyrimethanil-resistant isolates were selected either in laboratory assays (5AP and 10a) or in air samplings in citrus packinghouses (1 $\mathrm{AP}$ and $\mathrm{BF}$ ) (see text for details). Isolate Pd is sensitive to all currently registered and new fungicides. all isolates, whereas TBZ was highly effective in reducing decay caused by one of the pyrimethanil-resistant isolates but not for three additional ones that were found to be TBZ resistant (Table 2).

In evaluation of sporulation capacity, fludioxonil-resistant isolates sporulated significantly less on decaying fruit, with ratings of 1.0 to 2.63 compared with the wild-type isolate, with a rating of 4.0 (Table 5). After fludioxonil treatment, sporulation on lemon fruit inoculated with the wild-type isolate Pd was significantly reduced to a rating of 0.25 . For three fludioxonil-resistant isolates, the degree of sporulation increased after fludioxonil treatment whereas, for the fourth isolate, there was no difference between treated and untreated fruit. All pyrimethanil-resistant isolates had high sporulation capacities, with ratings of 4.0 (Table 6). After treatment with pyrimethanil, sporulation was significantly reduced in inoculations with the sensitive and resistant isolates (ratings of 1.65 to 2 ).

Visualization of qualitative and quantitative types of fungicide resistance on fungicide selection plates after air sampling of $P$. digitatum populations in citrus packinghouses. Spiral gradient air-sampling plates amended with imazalil or TBZ were exposed in a citrus packinghouse where resistance to these fungicides was known to occur. Selection plates for both fungicides at local concentrations $\leq \mathrm{EC}_{95}$ again showed an outer concentric ring with a high colony density $\left(>100 / \mathrm{cm}^{2}\right)$ (Fig. $2 \mathrm{~A}$ and B). For both fungicides, a large number of colonies was present at higher fungicide concentrations toward the center of the plate, and these colonies sporulated after 5 days of incubation. The spatial distribution of these latter colonies was markedly different for the two fungicides. For TBZ, there was a distinct border between the high-density outer ring and the lower-density inner zone, and

TABLE 5. Sporulation of Penicillium digitatum isolates with different sensitivities to fludioxonil on lemon fruit treated with fludioxonil

\begin{tabular}{|c|c|c|c|c|c|}
\hline \multirow[b]{3}{*}{ Treatment ${ }^{\mathrm{y}}$} & \multicolumn{5}{|c|}{ Rating $^{z}$} \\
\hline & \multirow{2}{*}{$\frac{\text { Wild type }}{\mathrm{Pd}}$} & \multicolumn{4}{|c|}{ Resistant isolates } \\
\hline & & FL7HR & FL12HR & $12 \mathrm{MR}$ & $13 \mathrm{HR}$ \\
\hline Untreated & $4.00 \mathrm{~A} \mathrm{a}$ & $1.27 \mathrm{C} \mathrm{b}$ & $1.27 \mathrm{C} \mathrm{b}$ & $2.63 \mathrm{~B} \mathrm{a}$ & $1.00 \mathrm{C} \mathrm{b}$ \\
\hline Fludioxonil & $0.25 \mathrm{~A} \mathrm{~b}$ & $2.60 \mathrm{~A} \mathrm{a}$ & $2.62 \mathrm{~A} \mathrm{a}$ & $3.13 \mathrm{~A} \mathrm{a}$ & $2.50 \mathrm{~A} \mathrm{a}$ \\
\hline
\end{tabular}

${ }^{\mathrm{y}}$ Fludioxonil was applied as an aqueous solution at $1,000 \mu \mathrm{g} / \mathrm{ml}$ using an airnozzle sprayer $12 \mathrm{~h}$ after inoculation.

${ }^{\mathrm{z}}$ Sporulation rating is based on a scale from $0=$ no sporulation to $4=$ fruit completely green. Incidence values followed by the same letter within a row (capitalized letters) or column (small letters) are not significantly different $(P>0.05)$ following an analysis of variance and least significant difference mean separation procedures. Fludioxonil-resistant isolates were selected either in laboratory assays (FL7HR and FL12HR) or in air samplings in citrus packinghouses (12MR and 13HR) (see text for details). Isolate $\mathrm{Pd}$ is sensitive to all currently registered and new fungicides.

TABLE 6. Sporulation of Penicillium digitatum isolates resistant to pyrimethanil on lemon fruit treated with pyrimethanil

\begin{tabular}{|c|c|c|c|c|c|}
\hline \multirow[b]{3}{*}{ Treatment ${ }^{\mathrm{y}}$} & \multicolumn{5}{|c|}{ Rating $^{z}$} \\
\hline & \multirow{2}{*}{$\frac{\text { Wild type }}{\mathrm{Pd}}$} & \multicolumn{4}{|c|}{ Resistant isolates } \\
\hline & & $5 \mathrm{AP}$ & $10 \mathrm{~A}$ & $1 \mathrm{AP}$ & $\mathrm{BF}$ \\
\hline Untreated & $4.00 \mathrm{~A} \mathrm{a}$ & $4.00 \mathrm{~A} \mathrm{a}$ & $4.00 \mathrm{~A} \mathrm{a}$ & $4.00 \mathrm{~A} \mathrm{a}$ & $4.00 \mathrm{~A} \mathrm{a}$ \\
\hline Pyrimethanil & $2.10 \mathrm{~A} \mathrm{~b}$ & $1.90 \mathrm{AB} \mathrm{b}$ & $1.79 \mathrm{BC} \mathrm{b}$ & $1.65 \mathrm{Cb}$ & $1.68 \mathrm{C} \mathrm{b}$ \\
\hline
\end{tabular}

${ }^{y}$ Pyrimethanil was applied as an aqueous solution at $1,000 \mu \mathrm{g} / \mathrm{ml}$ using an airnozzle sprayer $12 \mathrm{~h}$ after inoculation.

${ }^{\mathrm{z}}$ Sporulation rating is based on a scale from $0=$ no sporulation to $4=$ fruit completely green. Incidence values followed by the same letter within a row (capitalized letters) or column (small letters) are not significantly different $(P>0.05)$ following an analysis of variance and least significant difference mean separation procedures. Pyrimethanil-resistant isolates were selected either in laboratory assays (5AP and 10A) or in air samplings in citrus packinghouses (1 $\mathrm{AP}$ and $\mathrm{BF}$ ) (see text for details). Isolate $\mathrm{Pd}$ is sensitive to all currently registered and new fungicides. 
colony density was quite uniform over the entire inner zone, indicating the presence of two populations of the fungus (Fig. 2A). For imazalil, there was a gradual decrease in colony density from the $\mathrm{EC}_{95}$ ring toward the center of the plate, indicating that isolates had a range of different sensitivities and that high concentrations of the fungicide were still completely inhibitory to fungal growth (Fig. 2B).

Colonies that were cultured from two areas (low and high fungicide concentrations) of imazalil and TBZ selection plates were evaluated for their fungicide sensitivity. For both fungicides, colonies from the outer zone were either sensitive or resistant to the respective fungicides whereas, for the inner zone, all isolates were identified as resistant (Table 7). $\mathrm{EC}_{50}$ values of resistant isolates for TBZ were all $>7.825 \mu \mathrm{g} / \mathrm{ml}$ and, for imazalil, they were 0.25 to $1.136 \mu \mathrm{g} / \mathrm{ml}$.
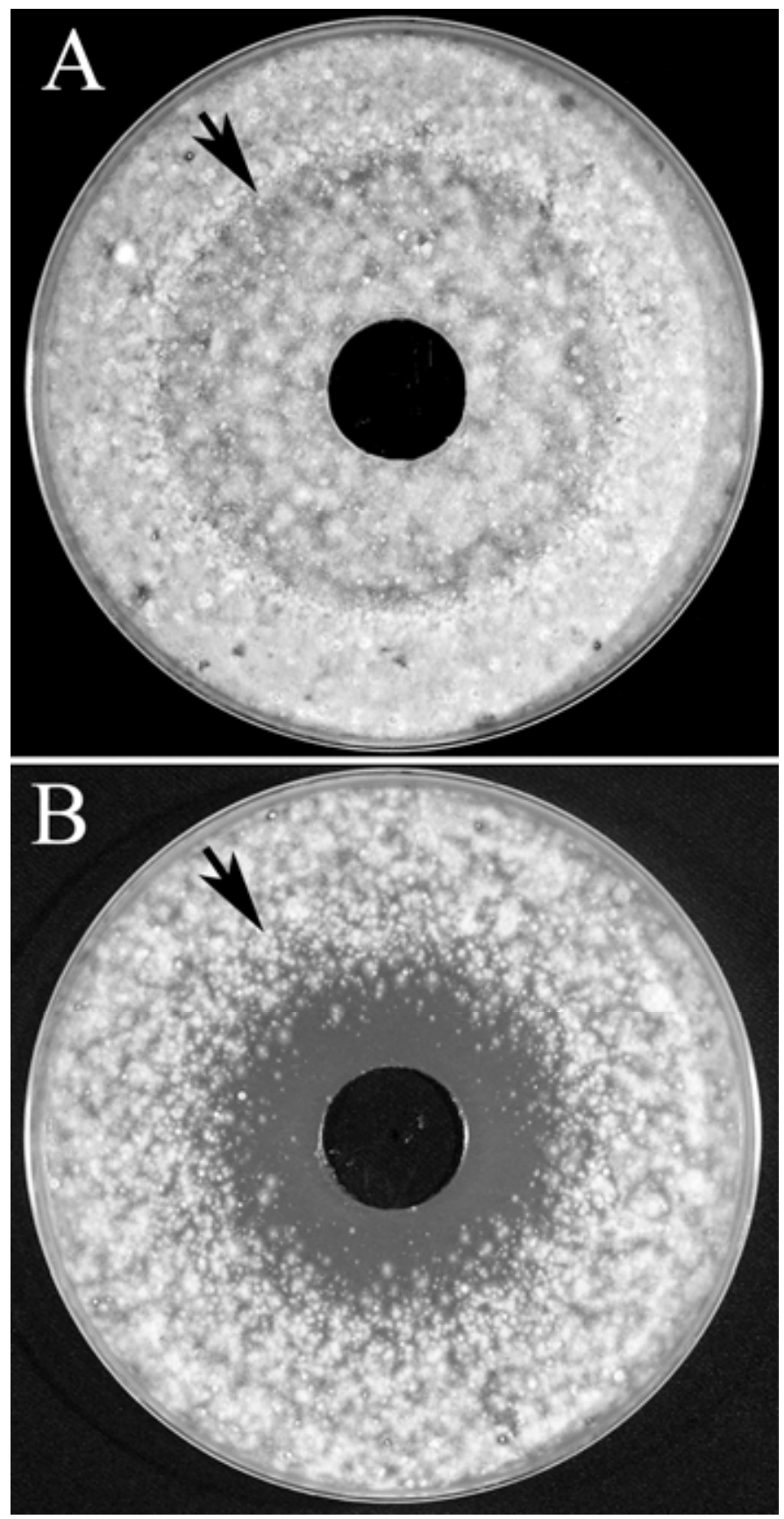

Fig. 2. Air-sampling spiral gradient dilution plates amended with A, thiabendazole (TBZ) or B, imazalil. Qualitative and quantitative resistance is visualized for TBZ and imazalil, respectively. Black arrows indicate the location of the $95 \%$ effective concentration of each fungicide.

\section{DISCUSSION}

The new spore air-sampling method described in this study allowed both visual assessment and quantitative analysis of a pathogen population regarding its fungicide sensitivity. Citrus packinghouses provide an ideal environment to use this method because spore densities of Penicillium spp. can be very high and, more importantly, there is a need for the continuous monitoring of fungicide sensitivities to aid in reassessing decay management strategies. Still, the method might be useful for other hostpathogen systems such as Penicillium spp. of pome fruit, where a similar high risk for resistance development exists, and in other systems, where high numbers of pathogen propagules are present. Because selection plates contain a wide gradient of fungicide concentrations (i.e., a 2.5-log concentration dilution from the center to the edge of a $15-\mathrm{cm}$ agar plate), the assay can be used for fungicides where resistance has not been characterized and where discriminatory concentrations needed for traditional singleconcentration selection plates have not been determined. $\mathrm{EC}_{95}$ ranges for sensitive baseline populations for each fungicide evaluated were derived from previous baseline sensitivity studies (13) and were positioned toward the outer edge of the plate. In our evaluations of large pathogen populations, this allowed most of the agar surface to be available for the selection of resistant isolates while, at the same time, visualizing the aerial spore density within the fungicide concentration range of $<\mathrm{EC}_{95}$. Realtime polymerase chain reaction technology has been suggested to be used for the screening of large mixed populations by others (4). This strategy, however, can only be used when all loci conferring resistance have been thoroughly characterized on a molecular basis. Still, isolates with noncharacterized resistance mechanisms will remain undetected unless fungicide-amended media assays are used.

Isolates of $P$. digitatum less sensitive to fludioxonil or pyrimethanil were readily recovered in packinghouse samplings although, at the time when these experiments were conducted, neither fungicide was in commercial use. Thus, these isolates were selected from natural populations in contrast to other studies where resistance in Penicillium spp. was generated by mutagenesis in the laboratory $(19,25)$. None of the selected isolates was resistant to both fludioxonil and pyrimethanil.

In our studies, we determined resistance frequencies by quantifying the number of $P$. digitatum colonies developing on fungicide-amended plates relative to the total number of spores deposited on control plates. Thus, this is the first time that natural resistance frequencies in a plant pathogen population were measured directly rather than theoretically estimated. Others have determined that thousands of isolates would need to be assessed to detect a resistant variant that occurs at a frequency of 1 in 1,000 within populations of Erysiphe graminis $(4,9,24)$. Using our method, we sampled hundreds of thousands of isolates in each replication and experiment (Table 1); thus, the large sample population provided the most accurate estimate of frequencies of natural variants within a fungal population. Samplings at the packingline where lemon fruit were taken out of storage and processed for shipping yielded much higher colony densities on the selection plates than samplings in storage rooms. Thus, most samplings were conducted at the packingline. Furthermore, resistance frequencies within a single fungal species were shown to be different for the two fungicides with different modes of action in both laboratory and packinghouse populations. Therefore, we have described an intrinsic characteristic of resistance potential in this pathogen that varies with the fungicide being tested. Resistance frequencies in most samplings were higher for pyrimethanil than for fludioxonil, indicating that pyrimethanil-insensitive isolates occur at higher frequencies within the wild-type population of the fungus. Resistance frequencies for both fungicides and the potential risk of these isolates to become established, however, 
must be considered high when taking into account the high reproduction potential of species of Penicillium.

Isolates with reduced sensitivity that occur at frequencies of $6.2 \times 10^{-5}$ or lower, as determined for P. digitatum in our study, are unlikely to be detected in baseline sensitivity studies where only a limited number of isolates is included. Thus, by sampling large populations, our method allows the early detection of rare variants. Additionally, based on their natural occurrence, these less-sensitive isolates should be considered part of the baseline population. Therefore, resistance monitoring more accurately could be based on changes in resistance frequencies compared with a baseline population rather than on sensitivities of a limited number of isolates of baseline and test populations. This approach is feasible for Penicillium spp. populations in citrus packinghouses using the method described in this study, and shifts in sensitivities in large populations can be detected at an early stage.

For our selection plates, we used PDA. A minimum growth medium for evaluation of anilinopyrimidine (AP) fungicides such as pyrimethanil was evaluated in our previous studies with $P$. digitatum (13). We found that mean $\mathrm{EC}_{50}$ values using the $\mathrm{AP}$ medium were slightly, although significantly, lower compared with PDA but were consistently proportional. Because the AP medium is laborious to prepare and requires much longer incubation times before fungal growth can be measured (i.e., 5 to 6 days compared with 3 days on PDA), we chose to do our studies using PDA medium.

In contrast to fludioxonil and pyrimethanil, only atypical, slowgrowing, nonsporulating colonies of $P$. digitatum were observed on azoxystrobin-amended selection plates that were exposed in citrus packinghouses. Thus, no resistance to azoxystrobin was detected in natural populations of this fungus, although resistant isolates were obtained by UV mutagenesis in the laboratory by others (25). This indicates that laboratory mutation studies may not give a realistic estimate of resistance risk. Resistance to QoI fungicides in the field has been described for a diverse range of fungal species, including powdery and downy mildew pathogens (11), as well as species of Mycosphaerella (7), Alternaria (20), and Venturia (18). In contrast, resistance to QoIs has not been reported to date for rust species and for Alternaria solani, and this has been correlated with the presence of an intron in the cytochrome b sequence directly after the codon for glycin at position 143, where mutations most commonly confer resistance (8). Such an intron, however, was not found in a comparison of laboratorygenerated resistant and wild-type sensitive isolates of $P$. digitatum (25); thus, this molecular characteristic cannot explain the absence of resistant isolates in our selections. Although no naturally resistant isolates were found in our evaluations of very large populations of $P$. digitatum, the risk of development of resistance to azoxystrobin in this pathogen cannot be ignored. Perhaps, resistance frequencies for this fungicide are lower than could be detected in our studies.

Similar to the packinghouse samplings, isolates of $P$. digitatum with reduced sensitivity to fludioxonil or pyrimethanil but not azoxystrobin also developed on our laboratory selection plates that were inoculated with diverse conidial mixtures of isolates sensitive to these three fungicides. Individual isolates of the mixtures were also mostly sensitive to imazalil and TBZ; thus, in contrast to the packinghouse selections, isolates less sensitive to fludioxonil or pyrimethanil were mostly sensitive to imazalil and TBZ. The selection of resistant isolates from mass platings of sensitive, single-spore isolates cannot be easily explained. Neither of the fungicides (i.e., pyrimethanil or fludioxonil) is known to be a mutagen; thus, other mechanisms must be responsible. Parasexuality has been demonstrated for $P$. chrysogenum, $P$. expansum, and $P$. italicum based on the presence of heterokaryons and the subsequent formation of segregants from diploids $(3,21)$. For $P$. digitatum, heterokaryosis could not be demonstrated positively (23) but rearrangement of genetic material in similar processes cannot be ruled out.

Representative isolates with reduced sensitivity to pyrimethanil were mostly similar to the sensitive wild-type isolate in their pathogenicity, virulence, and sporulation capacity. In contrast, anilinopyrimidine-resistant isolates of Botrytis cinerea were highly variable in their levels of sporulation but, on average, produced more spores on diseased host tissue than sensitive isolates (2). For fludioxonil, all isolates of $P$. digitatum in our studies were pathogenic but varied widely in their virulence and sporulation capacity. In addition, as described previously (15), isolates less sensitive to fludioxonil were variable in their in vitro sensitivity to the fungicide and were categorized as either moderately or highly resistant. Moderately resistant isolates from the laboratory selections all had relatively high $\mathrm{EC}_{50}$ values (close to $1 \mu \mathrm{g} / \mathrm{ml}$ ) whereas those from the packinghouse displayed a wider distribution of sensitivities. This can be explained by the use of singlediscriminatory concentration (i.e., $10 \mu \mathrm{g} / \mathrm{ml}$ ) selection plates in the laboratory in contrast to selection plates in the packinghouse studies that contained a wide fungicide concentration range. Because insensitivity to pyrimethanil occurred at a higher frequency and insensitive isolates were all highly resistant and sporulated at the highest rating, the risk of field resistance to develop to this fungicide is likely to be higher than for fludioxonil. Still, isolates from both fludioxonil and pyrimethanil selection plates were stable in their fungicide sensitivity characteristics after several passages on nonamended agar, and disease could not be sufficiently controlled after treatment with the respective fungicides at a rate common to the commercial label of each fungicide. Thus, under selection pressure, these isolates could become predominant in a population. Studies on the com-

TABLE 7. Fungicide sensitivity of Penicillium digitatum isolates collected from selected locations of thiabendazole- (TBZ) or imazalil-amended spiral gradient dilution (SGD) plates used in air samplings in citrus packinghouses

\begin{tabular}{|c|c|c|c|c|c|c|}
\hline \multirow[b]{2}{*}{ Type of resistance ${ }^{w}$} & \multirow[b]{2}{*}{ Fungicide } & \multirow[b]{2}{*}{ Selection area on SGD plate ${ }^{\mathrm{x}}$} & \multirow[b]{2}{*}{ Sensitivities $^{y}$} & \multirow[b]{2}{*}{$n$} & \multicolumn{2}{|c|}{$\mathrm{EC}_{50}(\mu \mathrm{g} / \mathrm{ml})^{\mathrm{z}}$} \\
\hline & & & & & Mean & Range \\
\hline \multirow[t]{3}{*}{ Qualitative } & TBZ & Outer zone & $\mathrm{R}$ & 9 & $>7.825$ & $>7.825$ \\
\hline & $\ldots$ & $\ldots$ & $\mathrm{S}$ & 11 & 0.205 & $0.059-0.852$ \\
\hline & $\ldots$ & & $\mathrm{S}$ & 0 & & \\
\hline \multirow[t]{2}{*}{ Quantitative } & Imazalil & Outer zone & $\mathrm{R}$ & 3 & 0.343 & $0.254-0.400$ \\
\hline & $\ldots$ & $\ldots$ & $S$ & 18 & 0.042 & $0.023-0.060$ \\
\hline
\end{tabular}

${ }^{\mathrm{w}}$ Qualitative and quantitative types of fungicide resistance (16) are represented by TBZ and imazalil, respectively.

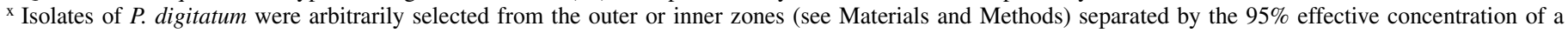
15-cm SGD plate.

${ }^{y} \mathrm{R}=$ resistant and $\mathrm{S}=$ sensitive.

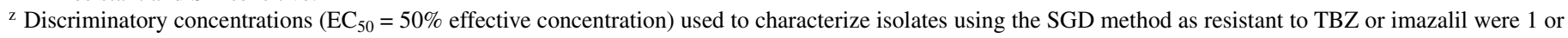
$0.15 \mu \mathrm{g} / \mathrm{ml}$, respectively. 
petitiveness of less-sensitive isolates for each fungicide in the presence of wild-type sensitive isolates will provide insight into their persistence in the absence of selection pressure.

Selection plates amended with TBZ or imazalil that were exposed in packinghouses where resistance to these fungicides was known to occur were used to visualize resistance quantitatively and qualitatively. Resistance was quantified based on the number of fungal colonies growing at fungicide concentrations $>\mathrm{EC}_{95}$ compared with lower concentrations. Resistance was qualified based on the distribution of colonies on the agar surface that differed between the two fungicide classes. The two growth patterns could be correlated with the two known types of resistance (16). The qualitative type of resistance for the benzimidazole TBZ that is based on a single genetic site was represented by two distinct subpopulations in regard to fungicide sensitivity, whereas the step-wise changes characteristic for quantitative resistance that is typical for the demethylation inhibitor group of fungicides (e.g., imazalil) were apparent as a continuous density gradient of colonies along the fungicide concentration gradient. Thus, the two types of resistance could be verified by mass samplings of fungal propagules on selection plates. Types of resistance could not be assigned to fludioxonil or pyrimethanil because a limited number of resistant colonies were obtained on each plate. The air-sampling method described is to serve primarily for monitoring purposes but eventually may be used, in part, to characterize presumptive resistance types if resistance phenotypes become prevalent.

The method described in this study is amenable for use in routine monitoring for resistance in airborne organisms where large populations can be sampled. During our relatively short exposure times, contamination of selection plates was negligible. For situations or host-pathogen systems that require plates to be exposed for longer times, the use of a selective medium may be necessary.

The results presented provide information for characterizing the resistance risks for the newly introduced citrus postharvest fungicides azoxystrobin, fludioxonil, and pyrimethanil for managing green mold. Because our method subjected large natural pathogen populations to selection, it is more likely to reflect the potential of the pathogen compared with the use of mutagens in the laboratory (24). Furthermore, properties of resistant isolates selected from natural populations will be more realistic because laboratory mutants may be affected at loci not involved in resistance. The ultimate establishment of resistant isolates in a population will depend on the interaction between stabilizing, directional, and disruptive selection forces as well as fungicide application strategies (24) and integrated disease management approaches, including sanitation practices.

\section{ACKNOWLEDGMENTS}

This research was financially supported by the California Citrus Research Board. We thank Dr. A. Soto-Estrada for technical assistance in air sampling of packinghouses; Janssen Pharmaceutica, Bayer CropScience, Syngenta Crop Protection, and Decco-Cerexagri Inc. for supplying fungicides and technical information; and the postharvest service companies Decco-Cerexagri, JBT (formerly FMC), and Pace International and the citrus growers' cooperation Sunkist for technical assistance during this project.

\section{LITERATURE CITED}

1. Bancroft, N., Gardner, P. D., Eckert, J. W., and Baritelle, J. L. 1984. Comparison of decay control strategies in California lemon packinghouses. Plant Dis. 68:24-28.

2. Bardas, G. A., Myresiotis, C. K., and Karaoglanidis, G. S. 2008. Stability and fitness of anilinopyrimidine-resistant strains of Botrytis cinerea. Phytopathology 98:443-450.

3. Barron, G. L. 1963. Distribution of nuclei in a heterocaryon of Penicillium expansum. Nature 200:282-283.

4. Brent K. J., and Hollomon, D. W. 1998. Fungicide Resistance: The Assessment of Risk. FRAC Monogr. No. 2. GCPF, Brussels.

5. Eckert, J. W., and Wild, B. L. 1983. Problems of fungicide resistance in Penicillium rot of citrus fruit. Pages 525-556 in: Pest Resistance to Pesticides. G. P. Georghiou and T. Saito, eds. Plenum Publishing Corp., New York.

6. Förster, H., Kanetis, L., and Adaskaveg, J. E. 2004. Spiral gradient dilution, a rapid method for determining growth responses and $50 \%$ effective concentration values in fungus-fungicide interactions. Phytopathology 94:163-170.

7. Fraaije, B. A., Lucas, J. A., Clark, W. S., and Burnett, F. J. 2003. QoI resistance development in populations of cereal pathogens in the UK. Pages 689-694 in: Proc. BCPC Int. Congr. Crop Sci. Technol. The British Crop Protection Council, Alton, Hampshire, UK.

8. Grasso, V., Palermo, S., Sierotzki, H., Garibaldi, A., and Gisi, U. 2006. Cytochrome $\mathrm{b}$ gene structure and consequences for resistance to Qo inhibitor fungicides in plant pathogens. Pest Manage. Sci. 62:465-472.

9. Hewitt, H. G. 1998. Fungicide resistance. Pages 135-181 in: Fungicides in Crop Protection. CAB International, Wallingford, UK.

10. Holmes, G. J., and Eckert, J. W. 1999. Sensitivity of Penicillium digitatum and $P$. italicum to postharvest citrus fungicides in California. Phytopathology 89:716-721.

11. Ishii, H., Fraaije, B. A., Sugiyama, T., Noguchi, K., Nishimura, K., Takeda, T., Amano, T., and Hollomon, D. W. 2001. Occurrence and molecular characterization of strobilurin resistance in cucumber powdery mildew and downy mildew. Phytopathology 91:1166-1171.

12. Kanetis, L., Förster, H., and Adaskaveg, J. E. 2007. Comparative efficacy of the new postharvest fungicides azoxystrobin, fludioxonil, and pyrimethanil for managing citrus green mold. Plant Dis. 91:1502-1511.

13. Kanetis, L., Förster, H., and Adaskaveg, J. E. 2008. Baseline sensitivities for new postharvest fungicides against Penicillium spp. on citrus and multiple resistance evaluations in P. digitatum. Plant Dis. 92:301-310.

14. Kanetis, L., Förster, H., and Adaskaveg, J. E. 2008. Optimizing efficacy of new postharvest fungicides and evaluation of sanitizing agent for managing citrus green mold. Plant Dis. 92:261-269.

15. Kanetis, L., Förster, H., Jones, C. A., Borkovich, K. A., and Adaskaveg, J. E. 2008. Characterization of genetic and biochemical mechanisms of fludioxonil and pyrimethanil resistance in field isolates of Penicillium digitatum. Phytopathology 98:205-214.

16. Kendall, S. J., and Hollomon, D. W. 1998. Fungicide resistance. Pages 87108 in: Fungicidal Activity. Chemical and Biological Approaches to Plant Protection. D. Hutson and J. Miyamoto, eds. John Wiley \& Sons, Chichester, UK.

17. Kinay, P., Mansour, M. F., Gabler, F. M., Margosan, D. A., and Smilanick, J. L. 2007. Characterization of fungicide-resistant isolates of Penicillium digitatum collected in California. Crop Prot. 26:647-656.

18. Köller, W., Parker, D. M., Turechek, W. W., Avila-Adame, C., and Cronshaw, K. 2004. A two-phase resistance response of Venturia inaequalis populations to the QoI fungicides kresoxim-methyl and trifloxystrobin. Plant Dis. 88:537-544.

19. Li, H. X., and Xiao, C. L. 2008. Characterization of fludioxonil-resistant and pyrimethanil-resistant phenotypes of Penicillium expansum from apple. Phytopathology 98:427-435.

20. Ma, Z., Felts, D., and Michailides, T. J. 2003. Resistance to azoxystrobin in Alternaria isolates from pistachio in California. Pestic. Biochem. Physiol. 77:66-74.

21. Pontecorvo, G., and Sermonti, G. 1953. Recombination without sexual reproduction in Penicillium chrysogenum. Nature 172:126-127.

22. Soto-Estrada, A., Kanetis, L., Förster, H., and Adaskaveg, J. E. 2004. A new air-sampling method for monitoring fungicide sensitivity and visualizing known types of resistance in Penicillium digitatum populations in citrus packinghouses. (Abstr.) Phytopathology 94:S97.

23. Strømnaes, Ø., Garber, E. D., and Beraha, L. 1964. Genetics of phytopathogenic fungi. IX. Heterocaryosis and the parasexual cycle in Penicillium italicum and Penicillium digitatum. Can. J. Bot. 42:423-427.

24. Wolfe, M. S. 1982. Dynamics of the pathogen population in relation to fungicide resistance. Pages 139-148 in: Fungicide Resistance in Crop Protection. J. Dekker and S. G. Georgopoulos, eds. Center for Agricultural Publishing and Documentation, Wageningen, The Netherlands.

25. Zhang Z., Zhu, Z., Ma, Z., and Li, H. 2009. A molecular mechanism of azoxystrobin resistance in Penicillium digitatum UV mutants and a PCR-based assay for detection of azoxystrobin-resistant strains in packing- or store-house isolates. Int. J. Food Microbiol. 131:157-161. 